\title{
IMPACTO DE LA INVASIÓN HISPANA SOBRE LOS INDÍGENAS RIOPLATENSES (1580-1640)
}

\section{Rodolfo E. González Lebrero'}

El presente artículo es una síntesis de la primera parte de un libro en preparación que estudia la etapa inicial de la ocupación hispana del área rioplatense. En ella, como en el resto de América, la llegada del invasor afectó en profundidad todas las manifestaciones de vida existentes en el territorio, sea en el corto o en el largo plazo. Los ecosistemas locales fueron alterados de manera notable y las poblaciones aborígenes se vieron sometidas a una violenta punción demográfica, a una crucial modificación de sus estructuras sociales y a una fuerte reconfiguración de sus relaciones territoriales. En las páginas que siguen concentraremos nuestra atención en el análisis de estos cambios.

\section{Los grupos humanos originarios}

Una gran cantidad de grupos indígenas fueron señalados por las fuentes históricas como ocupantes de aquel espacio, sin que los "territorios" mencionados puedan ser asignados como de uso exclusivo de ninguno.

Por su relación con la ciudad de Buenos Aires, se destacan cinco de esos grupos aborígenes: los guaraní, los chaná (con diversas combinaciones como chaná-timbú o chanámbeguá), los mbeguá (tal vez parte de los chaná), los querandi y los charrúa. Junto a ellos,

1 Universidad Nacional de Luján y Ciclo Básico Común de la Universidad de Buenos Aires. 
las fuentes describen otros grupos (yaro, minoano, guenoa, bohane, timbú, carcarañá, coronda, quiloaza, colastiné) cuyo contacto con los habitantes de Buenos Aires fue al parecer menos intenso, aunque es probable también que algunos de ellos fueran parcialidades de los grupos "principales": es el caso de minoanos, bohanes, guenoa y yaro que han sido incluidos dentro de la familia lingüística charrúa². A todos ellos debemos agregar a grupos cuyo hábitat los hispanos ubicaban en las sierras de Tandil y que por ello llamaron serra$\operatorname{nos}^{3}$.

Algunas dificultades aparecen a la hora de establecer con claridad la distinción entre todos estos grupos, tema que a desatado interesantes debates entre los investigadores ${ }^{4}$. La similitud de las piezas encontradas en diferentes yacimientos arqueológicos, así como la variabilidad en las costumbres enterratorias, muestran un intercambio cultural intenso, al menos entre las tribus de la llanura y las de la porción inferior del Paraná (querandi, mbeguá, chaná); los guaraní mantendrían cierta distancia con todas ellas. La difusión de algunas técnicas de caza y el uso de instrumentos similares (las boleadoras aparecen en casi todos los grupos) también indican contactos intergrupales, cuando no una más fuerte identificación, mientras que la recurrencia de algunas otras pautas culturales (cortes de dedo a la muerte de algún familiar, por ejemplo) pueden señalar un tronco originario común (guaycurú tal vez) de algunos de ellos. Estos cruzamientos hacen que, con la excepción de los guaraní, sean los acuerdos y las alianzas intertribales lo que caracterice a los grupos indígenas locales más que las situaciones de guerra.

También las fuentes históricas señalan los parecidos entre los grupos contactados por el invasor; vaya como ejemplo el comentario de Díaz de Guzmán quien, al señalar que cerca de la ciudad de Buenos Aires vivían varias naciones indias, destaca que

".... si bien tenian diferentes lenguas son de la misma calidad y costumbres que los querandi, enemigos

2 Hernández, (1992: 85). Los primeros cronistas usaron la lengua guaraní (palabras como querandí o Tubichaminí tienen este origen) para nombrar a los grupos con que se relacionaron. La propia hueste de Garay incluía un numeroso grupo de indios guaraní. Los nombres que aparecen más tarde (yaro, güenoa) bien pueden ser la forma en que las tribus se autonombraban y referirse por tanto a grupos ya mencionados.

3 Según Canals Frau se llamaban serranos a los indígenas del grupo puelche-guénaken o patagones del norte, con los que habría tomado contacto Garay en 1582 por primera vez.

4 Véase una síntesis de ellos en Conlazo (1990) y Hernández (1992). 
mortales de los españoles, y siempre que pueden ejecutar un acto traicionero no titubean en hacerlo. Aguas más arriba hay otros llamados los Timbú ${ }^{\prime \prime 5}$.

En definitiva, como bien señala Alicia Tapia "es imposible concebir la existencia de culturas aborígenes como entidades cerradas, estáticas y ubicadas en áreas culturales delimitadas"; se daría más bien "una elevada interacción dinámica entre las diferentes sociedades nativas porque fueron sistemas sociales dinámicos, abiertos al contacto cultural con otros grupos indígenas y con los diferentes segmentos sociales europeos y criollos"

\section{El primer capítulo en la violación del espacio indigena}

No fueron pequeños los cambios que afectaron de manera significativa al ámbito geográfico, tanto por la decisión de los hombres orientada a adaptarlo a sus necesidades, como por la menos voluntaria pero de todos modos dramática acción que plantas y animales exóticos ejercieron sobre aquel. Razones de espacio nos impiden desarrollar aquí este aspecto del problema.

Centraremos entonces el análisis exclusivamente en las graves consecuencias que la invasión europea implicó para los grupos indígenas dado el interés del español por subordinarlos a sus necesidades, aunque el dominio se ejerciera de manera desigual a lo largo del continente. En el Río de la Plata, al igual que el sur de Chile o el norte de México, las características de las culturas autóctonas pusieron fuertes límites a las exigencias del grupo invasor. Pero no por ello se librarían los aborígenes rioplatenses de sufrir profundas transformaciones de todo tipo.

Los españoles actuaron en toda América como si la tierra estuviera culturalmente vacía, sólo habitada por hombres a los cuales, si podían servir a los intereses de los invasores, se les debian modificar sus pautas socio-culturales para facilitar su incorporación al sistema económico dominante, (objetivo que la acción religiosa ayudó a cumplir) o debían ser destruidos si entorpecían aquellos intereses. No escapó el Río de la Plata a esta norma: en mapas y cartas geográficas de la zona se llama desierto a las pampas habitadas por las et-

5 Cit en Lothrop (1932: 102).

6 Tapia (1997). 
nias nómades locales ${ }^{7}$, calificación que perdurará hasta el siglo XIX. Sobre los habitantes de tal desierto descargarán los blancos diversas acciones a fin de someterlos y/u desplazarlos de su hábitat.

\section{La violencia guerrera}

Como en la mayoría de las regiones de América, las guerras contra el indio se inician en la región a poco de llegados los invasores: tanto las expediciones de Solís, Caboto y Mendoza, como las huestes de Garay tuvieron enfrentamientos violentos que implicaron golpes a la demografía indigena.

El primer contacto inicia la serie trágica: a poco de llegar al Río de la Plata la expedición de Solís sostiene en 1516 un enfrentamiento con un grupo guaraní, tal vez en la isla Martín García. Con la tercer expedición española que toca el Plata (la de Magallanes, en 1520, apenas tuvo contacto con el área) en 1526, continúa la saga. En la información que Gregorio Caro hizo contra su jefe Sebastián Caboto se lee

"Y después de haber estado alli algunos dias (en la desembocadura del Carcarañá, nota nuestra) y haber tomado trato e conversación con los indios de aquella tierra, estando todos pacíficos e concordes, el dicho Sebastián Caboto sin causa ni razón alguna afrentó e injurió los mas principales de los dichos indios, que eran amigos, y mató algunos dellos (...) Y asi en el dicho río del Paraguay como en otras partes donde tomó puerto hizo muchos agravios y mal tratamientos a los indios, matando e hiriendo muchos dellos estando descuidados, recibiéndolo los dichos indios con paz y amistad" ${ }^{\prime 8}$.

Enumeremos rápidamente los combates conocidos: en 1536, resistiendo las obligaciones impuestas por el invasor, diversas tribus se coalicionaron para atacar a la Buenos Aires de Mendoza en el día de Corpus Christi. En 1583 las luchas habidas con un grupo de indios a unas cuatro leguas de la ciudad recién fundada, Riachuelo arriba, acaudillados por el cacique Telomian Condie producen tal cantidad de muertes de naturales que varios autores han afirmado era este el origen del nombre del pago de la Matanza?.

7 Ejemplos en Martínez Sierra (1975: 93-94).

8 "Información hecha en las islas Azores por el capitán Gregorio Caro contra Sebastián Caboto" del 7/8/1530" cit. en Rodriguez Molas (1985: 151).

9 Marfany (1940: 16); Conlazo (1990: 22). Para Lothrop estos indios serían una coali114 
Instalados ya los invasores, la violación de pactos ocasionará nuevas luchas. El mismo año 1583 Juan de Garay fue muerto en combate contra los querandí del cacique Guren - Manuá, alzados ante el incumplimiento de acuerdos preestablecidos; dos años más tarde los españoles ejecutaron, luego de su juzgamiento, al cacique junto a otros miembros de su tribu ${ }^{10}$, lo que empujó a los querandí a la venganza, atacando Buenos Aires, aliados con indios mbeguá, quiloaza y guaraní. Otra violación por Garay de pactos establecidos con dos caciques guaraní (Yamandú, de las islas inferiores del Paraná, y Tein, litoraleño), explica el sitio a Santa Fe realizado por el mencionado Tein".

Los combates reconocían otros orígenes: la necesidad de fuerza de trabajo para lo cual debian someterse a las poblaciones locales, se desplegó a través de verdaderas expediciones de caza de indios llamadas malocas ${ }^{12}$, como aquellas de las cuales informa el gobernador Valdés y de la Banda en mayo de 1599:

“desde que llegué aquí demás de haber entendido en la residencia y enviado a dos malocas, la una vez la mitad de los vecinos y la otra la otra mitad y entre ambas veces se toparon indios de guerra y se les trajo la chusma y han venido a servir, y trato de que hagan asiento en parte cierta para que se conviertan a nuestra santa fe y se les ponga iglesia y doctrina y de la chusma que se les trajo se han bautizado cerca de 30 muchachos y muchachas y a los que estaban antes cristianos y que sirven se les ha hecho una iglesia en cierta estancia donde se van recogiendo" ${ }^{13}$.

El relato es suficientemente explícito sobre los métodos usados:

"se mataron los indios que allí habían, unos despeñados y otros a arcabuzasos y cuchilladas que serían co-

ción de tribus vecinas (p. 11). Conlazo, con razonable argumentación, sostiene que era éste un grupo "que venía del interior pampeano, posiblemente atraído por la instalación de los españoles" (p. 22). Para Hernández (1992: 168) se trataría de indios guaraní. Lo cierto es que, luego de su derrota, la parcialidad fue entregada al vecino Juan Ruiz de Ocaña "con tal que la doctrinéis y castiguéis y pongáis en policía según y como su majestad lo manda por sus provisiones..." cit en Moreno (1996: 220).

10 Hernández (1992: 140).

11 Azara, cit. en Hernández (1992: 140).

12 La palabra maloca significa vivienda en guaraní por lo cual salir a maloquear implicaba atacar sus poblados. El uso del vocablo se generalizó para aplicarlo a cualquier expedición de caza de indios. Conlazo ha propuesto con razón llamarlas simplemente malones... de los blancos.

13 Carta al rey del 20/5/1599 en Museo Etnográfico (en adelante ME) carpeta B, nro. 5. 
mo ciento setenta sin dejar uno con vida de los que peleaban y se trajeron otros ciento setenta muchachos y muchachas $^{114}$.

Entre el invierno y la primavera de aquel 1599, algunas de las parcialidades que habían sido en principio sometidas comienzan a resistirse, por lo que el mismo gobernador Valdés decide tomar medidas:

"Cuando el dicho gobernador partió al efecto en el dicho, habia enviado a los dichos soldados a asegurarse de unos indios que están alborotados y eran de los que á (hace, nota nuestra) más tiempo que sirven en esta tierra, tenian recogida su chusma y estaban con las armas en las manos, muchos juntos; túvose habla con ellos y hablaron con mucha soberbia; los soldados se volvieron pareciéndoles que no eran parte con tantos. A la hora que esta razón se escribe que son diez y ocho de Sevilla, parten (20) soldados al castigo de estos indios que están diez leguas de esta ciudad y quedaban prestando otros 20 que quedan para ir a castigar otros indios que también se han alborotado 25 leguas de aqui" ${ }^{15}$.

Algunas luchas implicaron el rapto de las mujeres indias: los soldados de Mendoza ya habían protagonizado batallas con este fin. Más tarde, en 1602, otra maloca realizada por el capitán Diego Nuñez del Prado hace algunas prisioneras, entre ellas la hermana de un cacique que entrega a otro vecino ${ }^{16}$. Este tipo de violencia sumó a la muerte en combate una baja en los índices de natalidad aborigen. También los jóvenes y niños fueron capturados, incorporándolos como criados a la sociedad blanca ${ }^{17}$.

14 Ibíd. Tal vez acciones como éstas fueron las que llevaron al sínodo de Tucumán en 1597 a quejarse de "las crueldades de algunos caudillos y soldados hacen, excediendo los límites de la justicia y humanidad y piedad cristianas, y causando en los indios horror y espanto de los españoles", Rodríguez Molas (1982: 18).

15 "Relación de lo que ha pasado con un navío que llegó a este puerto de Buenos Aires a los veintinueve de julio de 1599 años" en Anales de la Biblioteca tomo IV, Buenos Aires - Coni - 1905, pp. 490-496.

16 El 24/9/1602 Alonso Muñoz vecino y encomendero del cacique Caguas de nación ducembes, afirma que el cap. Diego Nuñez del Prado con consentimiento de los vecinos hizo "un compromiso para que en las malocas que se hiciesen no se repartiesen los hijos ni hermanos y parientes del mencionado cacique" a pesar de los cual "el dicho capitán salió a una maloca que hizo a la sierra (y) dio en unos indios del dicho cacique" y se apropió y repartió, entre otros a la hermana del cacique, que entregó al vecino García Víctor (AGN, sala 9, 19-1-4, folio 9).

17 Tales raptos no constituian novedad en las prácticas guerreras: de hecho los querandi, antes de entrar en combate, ocultaban a sus mujeres e hijos, Lothrop (1932: 22). 
Algunas de estas capturas tuvieron como objetivo convertir en rehenes a los indigenas apresados para obligar a las tribus a negociar y "domesticarse". En 1604 el cacique Juan Bagual huye de su reducción y asedia a los porteños. Su rebeldía se extendió hasta 1610 cuando, luego de atacar a un grupo de españoles en el camino a Córdoba, es obligado a someterse. En el informe al rey del 30 de abril de ese año, el gobernador Marín Negrón dice que le han

"traído preso a un cacique que llaman el Bagual con 70 vasallos que por no ser culpados con los demás vinieron con una cruz a pedir paz a los soldados, si bien es verdad que le parece que les obligó el hallarlos apoderados ya de sus mujeres e hijos..."18.

No será ésta la última rebeldía. En 1627, la presencia de un buque holandés en el Río de la Plata da pié a grupos de serranos para intentar un ataque a Buenos Aires, en alianza con los pampas. En esa ocasión el gobernador Céspedes organiza la represión, captura y reduce a muchos de ellos, logrando pacificar por algún tiempo la campaña ${ }^{19}$. Descriptos como buenos jinetes y belicosos, estos serranos lograron "alborotar" poco más tarde (en 1635) a los indios reducidos, por lo que se envia a sus toldos una expedición que logra hacer varios prisioneros, trasladándolos a Buenos Aires ${ }^{20}$.

El peso de esta violencia guerrera contra las tribus locales tuvo una incidencia muy fuerte en su caída demográfica. Algunos autores sostienen que los grupos querandí fueron "prácticamente exterminados en los primeros choques con los conquistadores"i2.

Asimismo, no puede descartarse el rigor al que eran sometidos los aborígenes en el trabajo como una causa adicional de muertes. La queja del Cabildo de Córdoba en 1608 por las obligaciones laborales impuestas en Buenos Aires a los indios que conducen las carretas desde aquella ciudad confirma lo dicho pues "haciéndoles hacer casas y edificios y otras ocupaciones en los que los tenían mucho tiempo (...) han muerto muchos indios..." 22.

$18 \mathrm{ME}$, carpeta $\mathrm{B}$, nro. 12. Este cacique permanecerá "sujeto" hasta su muerte.

19 Sierra (1981, tomo II: 163).

20 Conlazo (1990: 25).

21 Conlazo (1990: 104).

22 Rodriguez Molas (1985: 142). 
Sin negar la importancia de las causas arriba enumeradas, las epidemias fueron aquí también una causa fundamental de la enorme mortandad de los indígenas en la zona, aseveración verificada por varias fuentes.

\section{Las epidemias}

Es muy probable que se deba a la acción microbiana la suerte de un grupo guaraní ubicado en la zona comprendida por los ríos Luján y De las Conchas (actual Reconquista), acaudillado por el cacique Collazare ${ }^{23}$. Las tierras ocupadas por esta tribu no se entregan en los primeros repartos a españoles ni criollos, tal vez como resultado de una negociación con aquel cacique o bien por la mala calidad del suelo, más bajo y pantanoso. Pero ya en 1604 las mercedes de tierras dadas a los vecinos Escobar y Muñoz se hacen en aquel sitio, y es probable que la cercanía con el asentamiento indígena actuara como incentivo para establecer establecimientos rurales donde utilizarlos como mano de obra. La presencia blanca se intensifica en el área por el crecimiento de la navegación fluvial que une Asunción con Buenos Aires, con resultados funestos: el P. Lozano, que visita la zona en la primer mitad del siglo XVIII, refiere que allí

"estuvo situada la reducción de los guazunambis, que eran seiscientas familias, pero ni aún el sitio de su población se supiera si no hubiera habido curioso que mas ha de 50 años hubiese anotado su asolación" ${ }^{24}$.

Varias epidemias se dieron en la ciudad en la época considerada: 1602 (viruela), 1605-07; 1609 (antrax); 1615; 1621 (viruela combinada con tifus); 1627 (viruela); 1638 (viruela); 1642 (tifus). En particular el "contagio" de 1605-1607 fue de suma gravedad. El sacerdote Baltasar Navarro, (quien realiza una visita a Buenos Aires en 1606) afirma que la mayor parte de los indios han faltado

"por causa de una gran pestilencia que ha habido y hay de presente que se ha llevado pueblos enteros de

23 Hay en la zona un arroyo llamado Guazunambí, que para algunos autores era el nombre del grupo: un sitio arqueológico sobre el arroyo Sarandí fue identificado por Lothrop como perteneciente a los "Guazunambí", grupo al que incluye entre los querandí (Lothrop, p. 101). Sin embargo el 9 de septiembre de 1610 se presenta F. de Salas ante el alcalde Víctor Casco con el indio Cuyaçere, de nación guaraní (mencionado como de nación jasches en otro documento) que sucedió al cacique Aguaça (difunto), pidiendo se le dé posesión ( $M E$, carpeta $B$, nro. 13). La similitud en el nombre de los caciques indica probablemente un parentesco, que fundamentaría la filiación guaraní del grupo.

24 Lozano (1873: 142). 
indios y en un pueblo también murió un religioso nuestro que los adoctrinaba de la misma enfermedad y otro está en lo último; y ha sido en tanto extremo esta mortandad que se han quedado en los términos de la ciudad de Santa Fe por recoger los trigos y maices y otras legumbres en los campos por falta de gente y en esta ciudad de $\mathrm{Buenos} \mathrm{Al}$ res ha dado la dicha peste con más extremo por lo cual han quedado los más de los vecinos sin un solo indio y me han certificado que las mujeres nobles y nacidas en España van al río por agua y si no se les provee de remedio sin falta se perderán estas dos ciudades..." ${ }^{25}$.

Según la declaración del capitán Lope Vázquez Pestaña del 27 de abril de 1607, en esos años hubo tal mortandad de naturales que, "murió el servicio con las pestes". Un vecino señala que de alrededor de 350 indios reducidos, han quedado sólo 50; propone que para remediar la falta de brazos se traigan negros de Angola ${ }^{26}$. Este último argumento es utilizado un año después por el gobernador Diego Marín Negrón quien en carta al rey pide se introduzcan esclavos en Buenos Aires afirmando que esto permitirá que los naturales "no se acaben, porque es el trabajo que padecen tan grande que si no se repara por algún camino tengo por sin duda que se acabarán en breve"27.

También el crecimiento numérico de los nuevos herbivoros facilitó la reproducción de las epizootias, que tuvieron un destacado papel tanto en las muertes de sus portadores como, al menos en algunas ocasiones, en la de los hombres. Así el 24 de marzo de 1609 el Cabildo informa que la "pestilencia que mata el ganado vacuno, ovejas, cabras y ganado de cerda", afectó incluso a los indios, que morían "repentinamente" ${ }^{\text {"28. }}$.

25 Carta al rey de Fray Baltasar Navarro del 21/2/1606 en ME, carpeta B, nro. 8.

26 Levillier (1915, tomo 1 (1606-1608): 135).

27 Carta del 15-6-1610 en Colección Peña (en adelante CP) 1610. En esto no hay un ápice de exageración como lo demuestran claramente las palabras del sacerdote Lozano, quien afirma, hacia mediados del siglo XVIII, que "los timbú, quiloasas y colastinés, eran naturales del distrito de Santa Fe, que por pestes o por guerras, se extinguieron del todo. Eran caribes antes de domesticarse con el comercio de los españoles" (Lozano, 1873: 428). Que la "domesticación" fuera la causa de la "extinción" no parece interesarle al buen sacerdote...

28 Acuerdos del extinguido Cabildo de Buenos Aires publicados bajo la dirección de José Juan Biedma. Bs. As. -Talleres Gráficos de la Penitenciaria Nacional - 1907 (en adelante AECBA) tomo 2, p. 148. Prudencio Mendoza ha atribuido esta epidemia al carbunclo bacteridiano (cit. en Giberti, 1970: 30): en el hombre la muerte rápida por neumonía que produce esta enfermedad (también llamada antrax ó fiebre esplénica) es la característica que 
La epidemia más importante sufrida en la ciudad fue la de viruelas que estalló en 1621. Esta vez casi se despuebla Buenos Aires y desde entonces nace el culto a San Roque como patrono contra esta enfermedad. Algunos testimonios son más que elocuentes: en el acuerdo del cabildo local del primero de julio de ese año, y teniendo en cuenta que el servicio de negros e indios ha muerto por la peste, se pide que los indios forasteros y oficiales que hay en la ciudad se repartan para hacer las sementeras. Un informe del procurador Mateo de Grado, iniciado el 5 de julio con el testimonio del presbítero Don Francisco de Trexo, tesorero de la Catedral de Tucumán y comisario de la Inquisición, es sumamente elocuente:

"Dixo que habrá dos meses poco más o menos que comenzó en esta ciudad una enfermedad como vigüelas y tabardillo entre los negros, la cual fue dando también entre los indios y en la gente moza y criaturas nacidas en la tierra de que morian en los principios algunas personas y después fue tanto el rigor de la dicha enfermedad que se pegaba como peste y muchas personas han muerto de ella en menos de veinticuatro horas sin haberse hallado remedio suficiente y de veinte días a esta parte a sido muy grande el daño que ha hecho porque han muerto en esta dicha ciudad de todo género de personas más de setecientas y por no poderse enterrar en las iglesias y cementerios y por el contagio se han enterrado muchas fuera de la ciudad en parte señalada para ello y ha habido dia de diez y seis cuerpos muertos y hasta hoy no ha cesado (...) y que mediante la mortandad tan grande que ha habido y hay de negros e indios del servicio de las chacras y estancias de los vecinos y moradores de esta ciudad están muchas despobladas y con tener otros años por este tiempo todos los labradores de esta ciudad hechas sus sementeras de trigo, cebada ni otras legumbres sabe y le consta a este testigo que el día de hoy no hay sembrado cosa de consideración que amenaza muy gran necesidad mayor que la que ha habido este año y el pasado..." ${ }^{29}$.

El 20 de julio se afirma que han muerto en dos meses más de mil personas de "todos estados" y siguen muriendo ${ }^{30}$.

A pesar de la prevención de los indios, que huyen cuando aparecen las epidemias, los conquistadores los vuelven a exponer una y otra vez a su mortal influjo. El 20 de marzo de 1622 el gobernador Góngora en carta al rey informa que en la reducción de Baradero (fundada en 1615) "se han muerto de peste más de 60 indios y otros se habían ausentado del temor de ella".

parece adecuarse al vocablo usado por nuestra fuente (agradezco a Juan Carlos Basso, médico veterinario, la información pertinente).

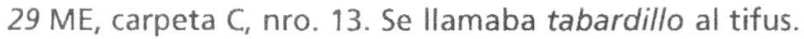

30 AECBA, tomo 6, p. 84-86. La cifra, tal vez algo exagerada, representa alrededor de la mitad de la población de la ciudad por entonces, incluyendo a los esclavos e indios. 
También en la del Bagual y en la de Tubichaminí se han retirado por lo mismo, pero Góngora logra en el primer caso que la tribu y el cacique vuelvan a su reducción; tanto Bagual como su hijo "están quietos y contentos", informa ${ }^{31}$.

Los efectos de la enfermedad no son sólo cuantitativos: el cruzamiento de linajes indios, reforzado por la caída demográfica, y las modificaciones en torno a las jerarquías fueron otras de sus consecuencias. En 1603, por un conflicto suscitado en torno a la encomienda del cacique Ayuare perteneciente a Miguel Gómez de la Puerta, nos enteramos del fin de los indios de su tribu: el mencionado cacique se traslada con los indios del cacique Cuyaguas a la chacra de Salas, una vez "muerta su gente por las viruelas". Ayuare se casa con una hermana de Cuyaguas y se incorpora de esta manera a la encomienda de Francisco de Salas. Este traslado motivó la protesta de Gómez de la Puerta ${ }^{32}$. La encomienda original de éste último era de un grupo querandi, mientras que el cacique Cuyaguas es de nación ducembes, probablemente mbeguá.

Las condiciones sanitarias de la ciudad favorecían la propagación de enfermedades entre quienes vivian o transitaban por ella. Aún no existían aljibes en Buenos Aires y el agua para el consumo se extraía del Río de la Plata. La ciudad carecía de organización higiénica colectiva y sólo se empezaban a tomar medidas aisladas de salubridad. Por ejemplo, en febrero de 1637 un bando del gobernador Dávila ordena mantener limpias las calles y no tirar en ellas basura, pregonándose, como era la costumbre, en los lugares de mayor concurrencia: conventos de Santo Domingo y San Francisco y ... en las pulperías ${ }^{33}$.

Los mataderos eran rústicos: simples corrales de madera, mal conservados dadas las insistentes quejas presentadas en el cabildo. Los cadáveres de perros, gatos y caballos se arrojaban a las calles donde entraban en putrefacción, constituyendo centros donde proliferaban las moscas. Lo mismo sucedía con las vacas sacrificadas sólo por los cueros. Las Iluvias contribuían sin duda a la limpieza de edificios y veredas, aunque traían aparejadas la formación de charcos que eran también fecundos criaderos de moscas y mosquitos que favorecieron la propagación de enfermedades epidémicas ${ }^{34}$.

$31 \mathrm{ME}$, carpeta C, nro. 14.

32 AGN, sala 9, 19-1-4 folio 49.

33 AGN, sala 9, 19-1-6.

34 Assadourian, Beato y Chiaramonte: 205. 
En la etiología de las epidemias, calamidades naturales como la langosta, el granizo, los incendios (el "fuego de las pampas") tuvieron sin duda algún rol. Pero la propagación de enfermedades contagiosas tuvo un agente fundamental en el movimiento de poblaciones foráneas (esclavos, soldados españoles e indios de otras provincias) que circularon por el puerto, y un fértil campo en los indígenas, por su indefensión biológica contra aquellas. Los navíos y las carretas fueron sin duda portadores de ratas y moscas infectadas. Las pestes de 1602, 1605 y 1642 se dieron en consonancia con expediciones militares. En los años 1615, 1621 y 1627, en cambio, la enfermedad apareció en principio en barcos negreros, propagándose con rapidez a pesar de las medidas tomadas, como la que en 1621 ordena que

"todas las personas sacadores de negros y otras que los tuvieses que hubiesen venido de mar a fuera los pusiesen en las últimas casas del pueblo y no habiéndolas se sacasen de él y se pusieran en toldos de cueros por causa de la peste" ${ }^{235}$.

De poco servía, como se ve, la selección que en sus lugares de origen realizaban los esclavistas, quienes trataban de embarcar sólo los negros sanos, en especial aquellos que hubieran sobrevivido a un ataque de viruela ${ }^{36}$.

El origen foráneo de las pestes y enfermedades era de sobra conocido por autoridades y vecinos, lo cual los indujo a tomar otras medidas de relativa eficacia. En el cabildo del 7 de marzo de 1611 se apoya el trueque propuesto por el vecino Antonio Fernández Barrios: éste entregaría al municipio su cuadra (que ocupaba la manzana delimitada por las actuales Defensa, Méjico, Balcarce, Chile) a cambio de la del Hospital (Reconquista, Sarmiento, 25 de mayo y Corrientes), argumentando el cabildo

"que sería más útil y conveniente hacerle (se refiere al hospital) en el camino que va al Riachuelo donde esté más cerca del comercio, y a causa de que aquel es el paso por donde entran en la ciudad la gente que viene por la mar y es donde vienen la mayor parte los pobres enfermos..." ${ }^{37}$.

Grandes protagonistas de la propagación de la enfermedad fueron las sequías, las cuales, al debilitar a quienes peor acceso a los recursos tenían (indios sometidos y negros sobre todo), los exponían sin piedad a la acción microbiana. Así, la peor epidemia de virue-

35 AECBA, tomo 6, p. 80.

36 Rodney (1982: 113).

37 AECBA, tomo 2. 
la que sufriera la ciudad en el período, coincide con la más severa sequía de la época (162021).

\section{Reacondicionamiento social: repartimientos y reducciones}

Un objetivo central que guió la política del español hacia los grupos indígenas fue su incorporación a las actividades productivas como mano de obra, tanto en actividades urbanas como rurales, con el resultado visible de la deculturación ${ }^{38}$ indígena. La primer distribución de indios a los vecinos de la ciudad se hace apenas dos años después de su fundación. En el documento de reparto aparecen consignados sesenta y cinco caciques, que se entregan a los vecinos con sus indios. De esos primeros repartimientos la mayoría no tuvo ningún efecto: cuando no mueren víctima de enfermedades los indios escapan al control blanco internándose en las pampas.

En realidad una combinación de elementos conspira contra los deseos del grupo dominante: tanto los patrones culturales de los aborígenes como una escasa capacidad militar de los hispanos para someterlos, más un ámbito geográfico que brindaba herramientas suficientes para la supervivencia, limitaron en gran medida la utilización de los grupos indios como fuerza de trabajo: en 1587, el tesorero Hernando de Montalvo afirma que al principio "venian a servir mas de seiscientos indios" pero luego de las represalias por la muerte de Garay, se retiraron a sus guaridas en los montes ${ }^{39}$. En 1603, Hernandarias impone el servicio obligatorio de los indios desde los trece hasta los sesenta años, con muy escasos resultados.

Otro mecanismo de deculturación fue la política de asentar a los naturales en reservas cercanas, tratando de impedir su dispersión geográfica, induciéndolos al trabajo agrícola; el mismo vocablo reducción tiene una connotación espacial innegable: a los aborígenes se les reduce el espacio que habitan, se les acotan sus límites...y su libertad. Ya en las Leyes de Burgos (1512-1513) se afirmaba que en las colonias "el principal estorbo que tienen los indios para enmendar sus vicios y que la doctrina no les aproveche, ni en ellos imprima, es tener sus asientos y estan-

38 "Entendemos por deculturación el proceso conciente mediante el cual, con fines de explotación económica, se procede a desarraigar la cultura de un grupo humano para facilitar la expropiación de las riquezas naturales del territorio en que está asentado y/o para utilizarlo como fuerza de trabajo barata, no calificada", Moreno Fraginals (1977: 14).

39 Cordero (1978: 39). 
cias tan lejos como los tienen y apartados de ios lugares donde viven los españoles".

Evidente ejemplo de la negación de los derechos indígenas sobre los territorios invadidos, las reducciones proliferaron en toda la América colonial. Ellas implicaron no sólo la violación de las formas indigenas de uso de espacio, sino también una importante modificación de sus relaciones jerárquicas: los misioneros, para poder someter a su voluntad a los grupos competían con los caciques y chamanes por su jefatura.

Buenos Aires no fue la excepción. En 1599 el gobernador D. Diego Rodríguez Valdés y de la Banda explicará así las dificultades de los vecinos:

“No tienen servicio los de este puerto de Buenos Aires a causa de ser los indios de esta tierra gentes que no tienen casas ni asientos y que a puro andar tras ellos los traen y con dádivas los sustentan y con todo eso se les van al mejor tiempo como yo lo he visto por los ojos por ser el tiempo de la siega cuando llegué aquín ${ }^{40}$.

Es decir que también en la región del Plata se enfrentaron dos concepciones opuestas en cuanto a las formas de ocupación del espacio. El seminomadismo indígena es visto por el invasor como una limitación a sus expectativas que debe resolverse. Por ello se establecieron, bajo la jurisdicción de Buenos Aires durante el período en estudio, varias reducciones, la mayoría de muy corta vida.

En 1611 la visita de Alfaro documenta la existencia de una reducción de indios (probablemente querandi) sobre el río Luján. De otras reducciones informa al rey el gobernador Góngora entre los años 1619 y 1621 :

"una nombrada San José del cacique Don Juan Bagual sobre el río de Areco, dieciocho leguas, poco mas o menos, del dicho puerto. Y otra dieciséis leguas del, tierra adentro, cerca del río Grande de la Plata, en la "isla de Santiago" nombrada del cacique Tubichamini. Y otra nombrada Santiago del Baradero que está sobre un brazo del rio grande del Paraná...."11.

En todos los casos las reducciones han recibido herramientas para la siembra, bue-

40 Carta del 20/5/1599 en ME, carpeta B, nro. 5).

41 Informe de Góngora al rey de mayo de 1620 en ME, carpeta C, nro. 11. Sobre la reducción del Baradero informa el Obispo Melgar que fue fundada con caciques chanás y algunos mbeguá y que para 1776, cuando escribe, ya estaba "extinguida la línea de los indios" (cit. en Canals Frau 1986: 274). Sin embargo esta reducción, fundada por Hernandarias en 1616, debió contar también con guaraní "de las islas", a los cuales ya estaban doctrinando los franciscanos. 
la que sufriera la ciudad en el período, coincide con la más severa sequía de la época (162021).

\section{Reacondicionamiento social: repartimientos y reducciones}

Un objetivo central que guió la política del español hacia los grupos indígenas fue su incorporación a las actividades productivas como mano de obra, tanto en actividades urbanas como rurales, con el resultado visible de la deculturación ${ }^{38}$ indígena. La primer distribución de indios a los vecinos de la ciudad se hace apenas dos años después de su fundación. En el documento de reparto aparecen consignados sesenta y cinco caciques, que se entregan a los vecinos con sus indios. De esos primeros repartimientos la mayoría no tuvo ningún efecto: cuando no mueren víctima de enfermedades los indios escapan al control blanco internándose en las pampas.

En realidad una combinación de elementos conspira contra los deseos del grupo dominante: tanto los patrones culturales de los aborígenes como una escasa capacidad militar de los hispanos para someterlos, más un ámbito geográfico que brindaba herramientas suficientes para la supervivencia, limitaron en gran medida la utilización de los grupos indios como fuerza de trabajo: en 1587, el tesorero Hernando de Montalvo afirma que al principio "venían a servir mas de seiscientos indios" pero luego de las represalias por la muerte de Garay, se retiraron a sus guaridas en los montes ${ }^{39}$. En 1603, Hernandarias impone el servicio obligatorio de los indios desde los trece hasta los sesenta años, con muy escasos resultados.

Otro mecanismo de deculturación fue la política de asentar a los naturales en reservas cercanas, tratando de impedir su dispersión geográfica, induciéndolos al trabajo agrícola; el mismo vocablo reducción tiene una connotación espacial innegable: a los aborígenes se les reduce el espacio que habitan, se les acotan sus límites...y su libertad. Ya en las Leyes de Burgos (1512-1513) se afirmaba que en las colonias "el principal estorbo que tienen los indios para enmendar sus vicios y que la doctrina no les aproveche, ni en ellos imprima, es tener sus asientos y estan-

38 "Entendemos por deculturación el proceso conciente mediante el cual, con fines de explotación económica, se procede a desarraigar la cultura de un grupo humano para facilitar la expropiación de las riquezas naturales del territorio en que está asentado y/o para utilizarlo como fuerza de trabajo barata, no calificada", Moreno Fraginals (1977: 14).

39 Cordero (1978: 39). 
cias tan lejos como los tienen y apartados de los lugares donde viven los españoles".

Evidente ejemplo de la negación de los derechos indigenas sobre los territorios invadidos, las reducciones proliferaron en toda la América colonial. Ellas implicaron no sólo la violación de las formas indígenas de uso de espacio, sino también una importante modificación de sus relaciones jerárquicas: los misioneros, para poder someter a su voluntad a los grupos competían con los caciques y chamanes por su jefatura.

Buenos Aires no fue la excepción. En 1599 el gobernador D. Diego Rodríguez Valdés y de la Banda explicará así las dificultades de los vecinos:

"No tienen servicio los de este puerto de Buenos Aires a causa de ser los indios de esta tierra gentes que no tienen casas ni asientos y que a puro andar tras ellos los traen y con dádivas los sustentan y con todo eso se les van al mejor tiempo como yo lo he visto por los ojos por ser el tiempo de la siega cuando llegué aquín ${ }^{40}$.

Es decir que también en la región del Plata se enfrentaron dos concepciones opuestas en cuanto a las formas de ocupación del espacio. El seminomadismo indígena es visto por el invasor como una limitación a sus expectativas que debe resolverse. Por ello se establecieron, bajo la jurisdicción de Buenos Aires durante el período en estudio, varias reducciones, la mayoría de muy corta vida.

En 1611 la visita de Alfaro documenta la existencia de una reducción de indios (probablemente querandi) sobre el río Luján. De otras reducciones informa al rey el gobernador Góngora entre los años 1619 y 1621 :

"una nombrada San José del cacique Don Juan Bagual sobre el río de Areco, dieciocho leguas, poco mas o menos, del dicho puerto. Y otra dieciséis leguas del, tierra adentro, cerca del río Grande de la Plata, en la "isla de Santiago" nombrada del cacique Tubichamini. Y otra nombrada Santiago del Baradero que está sobre un brazo del rio grande del Paraná..."41.

En todos los casos las reducciones han recibido herramientas para la siembra, bue-

40 Carta del 20/5/1599 en ME, carpeta B, nro. 5).

41 Informe de Góngora al rey de mayo de 1620 en ME, carpeta C, nro. 11. Sobre la reducción del Baradero informa el Obispo Melgar que fue fundada con caciques chanás y algunos mbeguá y que para 1776, cuando escribe, ya estaba "extinguida la línea de los indios" (cit. en Canals Frau 1986: 274). Sin embargo esta reducción, fundada por Hernandarias en 1616, debió contar también con guarani "de las islas", a los cuales ya estaban doctrinando los franciscanos. 
yes y granos, a pesar de lo cual el gobernador constata decepcionado que en dos de ellas no han hecho sus sementeras ni tienen vacas ni ovejas, persistiendo en su costumbre de alimentarse de "potrillos, venados y caza que matan" ya que estos indios no "tienen policía en nada, los más andan desnudos con unas mantas de pellejos; son holgazanes, huyen del trabajo". Sólo en la reducción de Baradero, donde a los chaná y mbeguá se le han sumado algunos indios guaraníiz, se practica la agricultura.

Concentraciones como éstas facilitaban el control sobre las tribus, además de la administración civil (cada reducción estaba a cargo de un español) y religiosa. La utilización de la fuerza de trabajo indígena en actividades agropecuarias explica la ubicación de algunas de las reducciones: es el caso de las organizadas en el río de Areco, cercana a varias estancias. Hacia el sur, a la reducción de los Tubichaminí se le asignó un doble papel: sujetar posible fuerza de trabajo para las estancias del pago de Magdalena y controlar a los grupos de indios serranos no sometidos. La cercanía de la ensenada de Barragán, utilizada con frecuencia para el comercio intérlope, permite pensar sobre un tercer rol del grupo en los trabajos portuarios que tal actividad suponía.

Por su parte, la reducción del Baradero estuvo destinada a garantizar la circulación fluvial del eje Buenos Aires-Santa Fe-Asunción. Como ha sido señalado ${ }^{43}$ ya Hernandarias habia establecido en diversos puntos varias reducciones combinando la circulación de productos indígenas y españoles. Sus palabras resumen bien el carácter estratégico de tales fundaciones:

"...Con las reducciones que he referido queda navegable este rio por estar fundadas en la ribera de él en puestos fertilísimos y abundosos para crianzas y labranzas y de muchas comodidades para los naturales porque tendrán salida de sus frutos y otras utilidades convenientes para su buen gobierno y conservación y los españoles mercaderes codiciarán esta navegación que tantas dificultades tenía así por la poca seguridad que hasta ahora ha habido en algunos parajes donde había indios de guerra como por ser navegación deleitosa y abastecida de comida, pes-

42 En una carta de Góngora del 20/7/1619 se informa que los indios del Baradero provenían de las "islas de Río Grande de la Plata y labraban la tierra y en ellas tenían doctrina" lo cual indica eran de nación guaraní (ME, carpeta $C$, nro. 7), conclusión coherente con lo narrado por el P. Lozano, quien refiere que en la fundación de esta reducción, debida al padre Fray Luis Bolaños, se juntaron indios "de las naciones guarani, albeguay (¿mbeguá?) y chaná" Lozano (1873: 140).

43 Areces, N. y otros, 1993: 24. 
quería y caza" ${ }^{44}$.

La caída demográfica en las reducciones se explica por la natural aversión del indio a ser "sujeto", pero también por la facilidad con que se propagaron en ellas las enfermedades. En la información levantada por el procurador Juan D. de Ojeda en 1606 se dice que antes de las pestes de 1605 y 1606 había 350 indios reducidos de los cuales quedaron para aquel año sólo cincuenta ${ }^{45}$. Asimismo, en 1621 el sacerdote Juan de llarraza se dolía de que en la reducción de Tubichaminí sólo quedaran cincuenta indios. A pesar del aporte de los oficiales reales que reconstruyen la reducción, en 1622 el gobernador Góngora informa que muchos de estos indios han muerto por las pestes y otros han huido por temor a ella, por lo cual "se los ha enviado a recoger y como por aquella parte es dilatada la tierra muy pantanosa y llena de lagunas no se han acabado de recoger todos" ${ }^{\prime 6}$. Una reducción Ilamada Nuestra Señora de la Estrella, ubicada a quince leguas al norte de la ciudad, diez leguas antes que la del Baradero, fue fundada en 1615 por Hernandarias quien afirma había cincuenta indios con sus mujeres reducidos y al cuidado de un cura franciscano ${ }^{47}$ pero ya no existe para 1619.

Los espacios donde se recluye a los indios ni siquiera son adecuados para su vida: en la reducción de Baradero "se han muerto de peste más de 60 y otros se habían ausentado del temor de ella y por ser malo el sitio, pantanoso y anegadizo, sin leña, mala agua y tener desviado el pescadero más de 3 leguas, despacho algunos caciques con dos españoles a buscar y recoger los indios que faltaban..." ${ }^{48}$ "

Un índice del grado de fracturación sufrido por las comunidades reducidas es la presencia en ellas de un número importante de aborígenes cristianizados. Esta condición supone al menos un doble reconocimiento: por un lado al sacerdote encargado de la reducción y por otra a sus jefes naturales. En la visita a las tres reducciones indias realizada en 1620 el gobernador Góngora, encuentra un total de 461 indios adultos, de los cuales 213

44 Carta de Hernandarias al Rey del 25/5/1616, cit. en Areces, N. y otros (1993: 24).

45 Levillier, 1915: 135.

$46 \mathrm{ME}_{1}$ carpeta $\mathrm{C}$, nro. 14.

$47 \mathrm{ME}$, carpeta $\mathrm{B}$, nro. 16. Esta reducción es fruto del traslado de los indios de la de San José, que desaparece.

48 Carta de Góngora al rey del 20/3/1622 en ME, carpeta C, nro. 14. 
son mencionados como "cristianos" (cuadro 1): tal vez sea ésta una cuantificación relativa de las tensiones que debieron generarse al interior de los grupos.

\begin{tabular}{|c|c|c|c|c|}
\hline \multicolumn{5}{|c|}{$\begin{array}{r}\text { Cuadro } 1 \text { / Población indígena en las re } \\
\text { Adultos }\end{array}$} \\
\hline Reducción & Cristianos & Infieles & & Total \\
\hline San José & 59 & 99 & 70 & 228 \\
\hline Tubichamini & 33 & 131 & 89 & 253 \\
\hline Baradero & 121 & 18 & 58 & 197 \\
\hline TOTAL & 213 & 248 & 217 & 678 \\
\hline
\end{tabular}

Estas tensiones se revelan con claridad en los trabajos arqueológicos. En la reducción de Baradero, como en San José, los cementerios están alejados del lugar donde se realizan las actividades domésticas y no se encuentran entierros secundarios ni ajuar fúnebre lo que revela cambios debidos al adoctrinamiento religioso realizado por los sacerdotes franciscanos. Estas modificaciones en las costumbres enterratorias indican "una modificación en el sistema de creencias y por lo tanto un fuerte quiebre de la tradición indígena"s0.

La descripción que realizara el P. Ovalle sobre los nómades de la pampa permite comprender lo que significó para ellos la política reduccional:

"Juzgan por el mayor bien de todos el absoluto y libre albedrío: vivir hoy en este lugar, mañana en el otro; ahora me da gusto gozar de la ribera y frescura de este río, y en cansándome de él paso a otro; quiero vivir un poco en los bosques y soledades, y en dándome gusto sus sombras salgo a los alegres prados y valles; aquí me entretiene la caza, alli la pesca; aquí gozo de las frutas que lleva esta tierra, y en acabándose me paso a otra, donde comienzan a madurar los que ella lleva; voy donde quiero sin dejar en ninguna parte prenda que me tire, que suele ser espina que de lejos atormenta; no temo malas nuevas porque no dejo atrás cosa que pueda perder; conmigo lo llevo todo, y con mi mujer y mis hijos, que me siguen donde voy, no me falta nada" ${ }^{51}$.

49 Se incluyen en la denominación de jóvenes "muchachos y muchachas de edad de menos de un año hasta edad de doce años (...) bautizados o por bautizar..."; a partir de los 13 años se los consideraba adultos y debían "servir" al blanco. Queda pendiente aquí la discusión sobre el sentido que tiene para el indígena esta "cristianización".

50 Tapia (1997).

51 Cit. en Canals Frau (1986: 221-222). El carácter nómade de los aborígenes locales ha sido discutido recientemente: ver Mandrini (1992). 
Esta imagen literaria, casi idílica, puede no compadecerse con la realidad: el indio está sujeto al medio en que vive tanto como cualquier otra sociedad humana. Sus movimientos si bien responden a las necesidades del grupo, están limitados por los recursos brindados por la naturaleza, y son, por ello, menos "voluntarios" o "libres" de lo que el autor deja entrever. Lo cual no obsta para afirmar que la sedentarización forzada que la reducción implicó fue una clara violación al uso que del espacio hacian estos grupos.

En la mayoría de los casos la sedentarización forzada implicó directamente el desarraigo de los grupos indígenas: la ya mencionada reducción de Santiago del Baradero, incluyó indios chaná, mbeguá y guarani y su número inicial fue de alrededor de doscientos cincuenta individuos; de los guaraníes dice un informe al rey que "se trajo a estos indios hace 4 años desde sus tierras, a 7 leguas de esta ciudad y 20 de la reducción" ${ }^{52}$. Al Baradero llegan también algunos chaná sobrevivientes de la destruida reducción de San Bartolomé, en la jurisdicción de la ciudad de Santa Fe, atacada por charrúa "de guerra" y chaná no reducidos ${ }^{53}$. Algunos de los indios del Baradero fueron otra vez trasladados cuando en 1624 se funda Santo Domingo Soriano, a la cual se agregaron más tarde indios charrúa ${ }^{54}$.

La reducción del Tubichaminí o de la isla de Santiago, fundada en primer lugar en 1615 y administrada por el vecino Alonso Muñoz Bejarano cerca de la ensenada de Barragán en la costa del río Santiago, pretendió contener a los grupos que respondían a ese cacique y que habrían participado del alzamiento de Juan Bagual, de quien Tubichaminí era yerno, y cuyo territorio se extendía hasta unas 10 leguas hacia el sur de la ensenada. Esta reducción se ha corrido hacia la depresión del Salado para 1619, ubicándose sobre el río llamado Todos los Santos ${ }^{55}$. Otro caso es la reducción de San José junto al río de Areco, refundada en 1610 con los indios "alzados" del cacique Juan Bagual, una vez derrotados. En 1604 , cuando se inicia la rebelión, este grupo ya estaba reducido.

52 Carta de Góngora al rey, del año 1620 (ME, carpeta C, nro. 10). Fue Hernandarias quien trasladó a este grupo, adoctrinado por entonces por los franciscanos en las islas del Delta. Las distancias señaladas en la carta coinciden con la zona ocupada por los Guazunambí (entre las Conchas y Escobar) por lo que podría tratarse también de ese grupo.

53 Areces, N. y otros (1993: 22-23).

54 Canals Frau (1986: 274-275).

55 Informe del padre franciscano Fray Joan de Darieta en ME, carpeta C, nro. 9. 
El que las reducciones se establecieran con indígenas de varios grupos señala el interés del invasor por impedir su cohesión interna. Pero además, en el envío de grupos ya deculturizados estuvo presente sin duda la intención de facilitar la dominación de los grupos indóciles, práctica que se empleó desde los primeros contactos en toda América. Las dificultades para dominar las etnias locales ${ }^{56}$ empujaron a los porteños a traer indios guarani, más proclives a aceptar el orden español. Con el mismo fin, los indios querandí fueron segregados de los grupos de indios tributarios, para evitar que les transmitieran sus sentimientos de rebeldía ${ }^{57}$.

El uso de traductores indígenas o españoles fue el modo empleado para facilitar la comunicación con los nuevos grupos que se iban contactando: el testimonio dado en Sevilla por Diego García (miembro de la expedición de S. Caboto) en 1530 indica que esta práctica se desplegó en el Río de la Plata apenas los hispanos se asentaron en la zona:

“...El capitán Diego García (...) trujo (a Sevilla, nota nuestra) tres indios que son los del río de Solís, que son libres, que son de la generación de los atambures (timbú, nota nuestra) (...) que estos tres indios los compraron en el dicho río de Solís por esclavos de otros indios enemigos suyos que son los guaranies, que los comen, y que este testigo, como capitán, los hizo libres a estos tres indios, y el que este testigo tiene, lo tiene para lengua para volver a la dicha tierra..." 58 .

Otra circunstancia vino en auxilio de esta política de dominación blanca: la llegada de indios de diversas lenguas y culturas producto de las nuevas relaciones espaciales que

56 Naturalmente remisos a su sometimiento, los indígenas se apoyaron en su profundo conocimiento de las características geográficas de la pampa para impedirlo, como descubre el gobernador Marín Negrón en carta al rey del 15/6/1610: "estos bárbaros desnudos son más fuertes y más duros de domar que cuantas naciones hay en el mundo..." lo que explica, entre otras razones, por que la tierra es muy espaciosa y poco poblada y por estar atravesada de ríos caudalosos y de muy grandes pantanos y ciénagas, lo cual dificulta su sometimiento (ME، carpeta B, nro. 13).

57 Saguier (1983: 334).

58 "Información levantada en Sevilla para averiguar los indios que Diego García y Sebastián Caboto habían llevado a España desde el Río de la Plata" (4/12/1530) cit. en Medina, (1908a: 178). Los españoles utilizaron con frecuencia a traductores de grupos ya "domesticados" para relacionarse con los otros. Esta estrategia de acercamiento se dio desde el inicio mismo de la invasión a América, y es fruto de la previa experiencia de la conquista de las Canarias. 
a la zona le imponen los intereses mercantiles de los hispanos, facilitó la tarea de prevención de rebeliones al tiempo que hacía de la lengua castellana una eficaz herramienta de deculturación. En un número difícil de determinar, llegan a Buenos Aires lules, diaguitas, olcos, juríes, comechingones, sanavirones, tonocotes y huarpes, además de los ya mencionados guaran ${ }^{39}$ incorporándose como mano de obra (forzada en algunos casos, más o menos libre en otros) a la economía porteña. El protector de los naturales en una petición de 1605 señala que

"en las chácaras y estancias del distrito de ella están algunos indios e indias de la gobernación del Tucumán y de Chile y del Perú en servicio de vecinos de esta ciudad que ha mucho tiempo que se sirven de ellos en sus haciendas y granjerías; y ni más ni menos en esta ciudad algunos indios oficiales y sin orden ni concierto que es justo haya y se tenga con ellos, se ocupan y trabajan sin cuenta ni razón...". Y como ello ocasiona perjuicio a los naturales ordena que "los dichos indios que así pareciere haber forasteros y acomodados con las tales personas hagan concierto del salario que han de ganar cada mes o cada año y que de ello, en mi presencia y con intervención mía, les hagan conocimiento para la seguridad de la paga y para que con el interés se puedan vestir y tratar como conviene y que no anden distraídos y maltratados..." ${ }^{60}$.

Se ve aquí que además de los indios alquilados en Buenos Aires por sus encomenderos del interior, hay un número importante de migrantes menos temporarias de lo que en principio podía parecer, huidos en algunos casos de las presiones ejercidas sobre sus comunidades, sea en trabajo, sea en tributo o por la pérdida de sus tierras a manos de los terratenientes ${ }^{61}$. Ya parcialmente deculturizados, estos indígenas fueron confiables para los pobladores hispanos, por lo cual se los empleó en diversas actividades laborales y hasta se les confió un rol en la defensa de la ciudad, como se desprende de las palabras del gobernador Céspedes cuando informa haber establecido dos compañías de lanzas y otra de infantería más

"otras dos de indios forasteros de a caballo de diferentes partes de estos reinos que están sirviendo en esta tierra porque los que hay en las Reducciones son mal seguros y antes conviene no saigan de ellas si hubiere ocasión; que lo tengo ordenado y a un Capitán de campaña que si los encontrare fuera de ellas los ahorque, que sin duda se juntarian con el enemigo.... ${ }^{62}$.

59 Saguier (1983: 335).

60 Petición de Pedro López Maldonado del 8/10/1605 en AGN, sala 9, 19-1-5f. 11 y 11 v. 61 Saguier (1993).

62 Carta al rey del 30/8/1631 en Manuscritos de la Biblioteca Nacional (en adelante BN) $N^{\circ} 4863$. 
Las migraciones de indios provocaron un proceso de rápida misegenación entre grupos muy diversos: a los matrimonios entre diferentes linajes indígenas de la zona provocados por la caida demográfica de las tribus, debemos agregarle aquellos concertados por los forasteros, que desposaban a las indias locales, llevándolas consigo al regresar a su tierra. Tales matrimonios fueron desalentados por los vecinos, dado el perjuicio económico que les causaba ${ }^{63}$. Como esta práctica prohibitiva continuó a pesar de todo, dos podían ser las soluciones adoptadas por el indio forastero: o bien (obligado por su encomendero, por ejemplo) deja a su mujer y, con ella, a su descendencia, y regresa a su tierra o bien decide quedarse (fugándose de su encomienda, siempre que estuviera sujeto a ella) incorporándose a la familia de la esposa: en ambos casos se violenta la patrilinealidad y virilocalidad predominante, quebrándose los linajes y los vínculos territoriales.

Pueden señalarse otros dos elementos que actuaron en el mismo sentido disgregatorio de las culturas indias. En primer lugar la división política del espacio hecho por los hispanos que conspira no sólo con la movilidad indígena y los intercambios entre diversos grupos, sino contra su unidad misma: las reducciones de Buenos Aires, Córdoba o Santa Fe afectan en algunos casos a las mismas parcialidades -hay reducciones chaná tanto en Santa Fe como en Buenos Aires y para 1617 existían al menos cuatro reducciones de indios querandi en la jurisdicción de Córdoba- desintegrándolas, a la vez que fragmentan el espacio indígena. En segundo lugar, aunque en pequeña medida dadas las escasas referencias halladas, algún papel jugaron también los amancebamientos de las mujeres indias del área bonaerense con los españoles. Cuando en 1603 Hernandarias dicta una serie de ordenanzas relativas a los indios, incluye una fuerte reconvención de estos amancebamientos, ordenando que el vecino

“...que así estuviere amancebado con india de su servicio, habiendo sido amonestado una vez por cualquiera justicia que sea y volviendo a reincidir en el dicho delito, y probándosele suficientemente, tenga perdida la tal india, la cual desde luego doy por vaca, para encomendarla en la persona que me pareciere..." ${ }^{64}$.

63 En una Real Orden de Felipe III al gobernador Marín Negrón en 1609 el rey escribe que teniendo en cuenta "que a las indias de esa provincia de los repartimientos que están encomendados no se les deja libertad para casarse porque si se casa la india de un repartimiento con un indio de otro el marido lleva a la mujer y el encomendero, porque no le saque la india de su encomienda, impide estos matrimonios", ordena castigar "estos excesos" (ME, carpeta B, nro. 9).

64 Cit. En Sierra, tomo II, (1981: 38). La víctima de este delito, según la ordenanza, no es la india sino la sociedad toda, por el "mal ejemplo" que supone: la india no ganará su li- 
En suma, el desarraigo y la desestructuración de las sociedades indias fueron los resultados perseguidos para facilitar por un lado el asentamiento de los recién llegados y la hispanización del territorio y, por otro, la construcción de una sociedad dual y estratificada donde a los aborígenes se les reservaba el escalón más bajo.

\section{Aportes de la sociedad blanca: ¿liberación o dependencia?}

Los dramáticos cambios sufridos por los grupos subordinados están a la vista pero øque sucedió con aquellos grupos que lograron mantener cierta independencia de la sociedad blanca? También ellos sufrirán transformaciones sociales profundas. Algunos de estos cambios están vinculados con la adopción del caballo, de manera similar a lo ocurrido en las praderas del oeste norteamericano. La proliferación de este ganado, a partir del abandonado por Mendoza, modificó los hábitos alimenticios y las modalidades de caza ${ }^{65}$. La mejora en el transporte permitió utilizar viviendas de cuero más grandes, a veces con techo y tres o cuatro paredes, apoyadas sobre palos ${ }^{66}$. Y aún las prácticas guerreras se transforman ya que

“los más son grandes hombres de a caballo y están prevenidos de armas de cuero de buey para sus personas y caballos. Usan lanzas, arcos, flechas, bolas y hondas y a su modo hacen los escuadrones en forma de media luna y los infantes sin parar en un lugar" ${ }^{\prime 67}$.

El dominio indígena sobre los caballos está documentado al menos desde 1599; ese año el gobernador Valdés y de la Banda informa al rey que los indios cercanos a la ciudad

"...por un cercillo o cuchillo darán un caballo (...) porque como señores de la campaña lo son de dos millones de yeguas y caballos que andan en ella, de los cuales comen y se sirven...." ${ }^{68}$.

bertad, siendo sometida a otra encomienda donde a su vez corre el riesgo, por cierto, de ser nuevamente "amancebada".

65 Las ventajas que el uso del caballo otorgó a las tribus indígenas han sido destacadas por Mandrini y Palermo, entre otros.

66 Lothrop (1932: 108).

67 Carta de Céspedes al rey del 15/7/1629 en Colección García Viñas (en adelante CGV) nro. 4835. Como se lee aquí, también el vacuno fue incorporado a la cultura indígena.

68 Carta al rey del 28/9/1599 en Levillier (1915, tomo I: 74). 
Una década más tarde (1611) los europeos reconocen que la cantidad de caballos y yeguas "silvestres" existentes en las llanuras "han dado ocasión a los indios andar a caballo y están ya tan diestros que no les da cuidado silla ni aparejo"69.

Boleadoras y lanzas (las largas, de más de 4 metros $^{70}$ ) reemplazaron asimismo al arco y la flecha en las cacerías. En el caso de los serranos, abandonaron por entonces la fabricación de cerámica e "inducidos por la movilidad que les permitía el caballo se dedicaron al pillaje, y fue entonces que, mezclados con grupos de pampas comenzaron a atacar las haciendas y estancias de los españoles"71. La lucha entonces entablada (y que durará doscientos años) en torno a los recursos económicos que sostiene el territorio, se acelerará hacia fines del siglo XVII.

Otros dos trascendentes cambios producidos en la economía aborigen ligados en parte al ganado mayor importado tienen consecuencias más profundas. Por un lado la incorporación de prácticas mercantiles (intercambio de animales por manufacturas) que formarán parte de las actividades económicas de los indios locales al menos desde los primeros años del siglo XVII. Los intercambios fueron impulsados por los propios invasores: a los indios que ha reducido les encarga Hernandarias capturar unas cuatrocientas yeguas cimarronas, cortar cerca de mil piezas de madera y quince mil cañas a cambio de un pagamento que nunca recibieron ${ }^{72}$. Tales intercambios reforzaron la relación hispano-indígena, aunque la violación de los acuerdos económicos provocara importantes conflictos.

La lista de productos que intervenían en esos intercambios no es pequeña: los pampas llevaban a la ciudad además del ganado cimarrón y maderas ya mencionados, plumas de ñandú, pieles, tejidos obtenidos en el trato con los grupos transandinos y cueros, productos que entregaban por vino y/o aguardiente, armas, herramientas (principalmente de hierro), yerba mate, azúcar y tabaco ${ }^{73}$, además de los collares de cuentas de cobre o ve-

69 Carta del gobernador al rey del 25/4/1611 en CGV, nro. 4121.

70 Mandrini (1993: 50).

71 Canals Frau (1986: 210).

72 Carta del gobernador Góngora al rey del año 1620 en ME, carpeta C, nro. 10.

73 Palermo (1988: 80). No todos estos productos estaban presentes en los intercambios 
necianas que aparecen con frecuencia en los enterramientos indígenas posteriores al contacto. Algunos de estos productos eran a su vez trocados por los pampa con otros grupos indígenas.

En particular la incorporación por los indios de algunos artículos de hierro tuvo no pocos efectos, ya que "para los pueblos cazadores, la posesión de objetos de hierro implica la posibilidad de mejorar armamento y facilita el laboreo del cuero y la madera: el utilaje de piedra, hueso o madera tiende a reemplazarse, al menos en parte, por elementos metálicos". A los guarani de las islas, por ejemplo, les significó sin dudas un avance para la construcción de canoas, tan necesarias para la pesca y la comunicación. En sociedades donde la guerra es una constante, "el ahorro de tiempo posible gracias a los instrumentos de hierro permitiría mayor dedicación a las actividades ofensivas o defensivas; el abandono forzoso o la destrucción de aldeas y sembrados a causa del enemigo podía ser rápidamente subsanado. Además, cuchillos, hachas y escoplos de hierro acelerarían la construcción de arcos, puntas de flecha de madera y mazas empleadas en los combates, y lo mismo pasaría con las canoas perdidas en la guerra o necesarias para ella"74.

Otros usos de las herramientas fueron bastante negativos: B. García, poblador de Asunción en 1556, afirma que en canje por estos artículos podían obtenerse indias de servicio; U. Schmidl dice que entre los carios o guaraníes "una mujer cuesta una camisa, un cuchillo, una hachuela, u otro rescate cualquiera" 75 . Además, las nuevas necesidades empujaron a los indígenas a mantenerse cerca de las poblaciones blancas, lo que implicó también una mayor dependencia de aquellas. Por otra parte, el paulatino abandono de los instrumentos o adornos tradicionales implicaba también la desaparición de los especialistas en su confección; así, una serie de conocimientos y técnicas se van perdiendo hasta desaparecer en el largo plazo.

El trueque de caballos por elementos de hierro o vestidos pudo modificar los roles y la distribución del poder al interior de las tribus. En su visita a las reducciones, Góngora

del período en estudio; el aguardiente, por ejemplo, no ingresa al mercado porteño sino hasta más allá de mediados de siglo.

74 Todo el encomillado del párrafo en Palermo (1986: 31 y 33).

75 Schmidl (1997:43). 
encuentra que "andan vestidos pocos con mantas y camisetas de lana y sombreros que los españoles les dan por caballos; los demás indios e indias se cubren con pellejos de animales"76, lo cual indica distinciones apoyadas en la apropiación diferencial del producido del arreo comunitario de los caballos cimarrones.

Por otro lado la economía mercantil expandió las relaciones espaciales de los indios bonaerenses con los araucanos a quienes proveyeron de equinos y vacunos, apoyo logístico clave para la guerra que sostuvieron contra los invasores de allende los Andes ${ }^{77}$. Facilitados por la disponibilidad de animales en la pampa estos intercambios darán como resultado la aparición de una economía pastoril indígena en las Ilanuras del sur bonaerense, proceso bien documentado para el siglo XVIII ${ }^{78}$. No sabemos cuando comenzaron los intercambios señalados, aunque es seguro que para las primeras décadas del siglo XVII ya se da$\operatorname{ban}^{79}$.

Esta construcción de redes de intercambio implicó el reforzamiento de la tendencia a la exogamia de los aborígenes locales: los matrimonios expresan la necesidad de alianzas para impedir, por un lado, posibles trabas a la circulación de mercancías, y por otro para reforzar los "negocios" de un grupo con otro. Las alianzas defensivas contra grupos recién venidos y hostiles a las etnias cazadoras puede constituir otra hipótesis explicativa: la llegada de guaranies primero y blancos después empujó al resto a incrementar tales prácticas. Si los aborígenes que atacaron la primera Buenos Aires eran efectivamente de diversos grupos, no parece extraño que reforzaran las alianzas guerreras con intercambios ma-

76 Informe del gobernador al rey de mayo de 1620 en $M E_{،}$ carpeta C, nro. 10.

77 Expandió, puesto que a la llegada del blanco tales contactos ya existían: en la expedición que realiza Garay hacia el sur en 1582 encuentra grupos indígenas que portan "alguna ropa de lana muy buena; dicen que la traen de la cordillera, de las espaldas de Chile" (cit. en Martinez Sierra, 1975: 125).

\section{Mandrini (1992: 67-68).}

79 En 1635 el gobernador Dávila instruye al jefe de una partida militar: “...Inquiriréis y sabréis con toda particularidad si es cierto que los indios del reino de Chile pasan la cordillera por esta parte y rescatan y llevan caballos para aquel reino y de quién se valen y con qué indios comunican y en que tiempo pasan la cordillera para esta banda y hasta donde llegan y qué género de armas tienen y que práctica tienen con los indios que comunican de estas pampas y distrito" cit. en Montoya (1984: 38-39). 
trimoniales. La exogamia cumple, en cualquiera de los casos, un rol político de importancia.

El crecimiento del ganado favoreció el desplazamiento hacia el área rioplatense de otros grupos indigenas ${ }^{80}$, enriqueciéndose así los intercambios interétnicos, que incluyeron también los matrimonios mixtos. Aunque más allá del período en estudio, uno de estos grupos, los araucanos, producirían importantes modificaciones en las etnias locales.

Otros animales europeos fueron adoptados por algunos aborígenes. Según refiere el cronista Oviedo, los timbú

“Tienen muchos perros como los nuestros, grandes y pequeños, que ellos estiman mucho, los cuales allá no había, y se han hecho de la casta que quedó cuando Sebastián Caboto y el Capitán Johan de Junco anduvieron por aquella tierra" ${ }^{81}$.

Los indígenas utilizaron al perro como apoyo a sus cacerías de guanaco o ñandú y más tarde, cuando aparece entre los pampa la economía pastoril, para el manejo del gana$\mathrm{do}^{82}$. En el informe de 1620 sobre las reducciones de la jurisdicción, el escribano Juan de Munarriz menciona la existencia de perros, junto a otros animales domésticos, en la del cacique Juan Bagual ${ }^{83}$.

Los indígenas asentados en el área urbana o en las reducciones recibieron básicamente maíz por alimento y sólo como excepción trigo; para los grupos originarios de la zona (a excepción de los guarani) esto significó la incorporación de cereales en su alimentación. Para aquellos que provenían de culturas agrícolas la única novedad en este plano fue la ingesta de trigo. Habrá que esperar que los estudios sobre los restos humanos pre y post

80 Incluso se ha sugerido que el sector comprendido entre el río Salado y las sierras de Tandilia se habría poblado después de la difusión del ganado europeo, pues la escasez de guanacos habría impedido la instalación humana (Madrazo, 1973). Las evidencias arqueológicas afirman, sin embargo, la presencia indígena prehispánica en la zona.

81 Cit. en Lothrop (1932: 130). No está definitivamente probada la presencia de canes prehispánicos, aunque algunas evidencias van en esa dirección (ver Palermo, 1988; Silveira, 1991; Mazzanti, 1993).

82 Palermo (1988: 64).

$83 \mathrm{ME}$, carpeta C nro. 10. También tenían gallinas de origen europeo. 
conquista descubran las consecuencias nutricionales y patológicas del cambio de dieta, sobre todo en los grupos más asimilados ${ }^{84}$.

En definitiva la incorporación de elementos europeos amplió el espacio ocupado por los indígenas no sojuzgados permitiéndoles establecer nuevas relaciones interétnicas o bien fortalecer las ya existentes, lo que facilitó su resistencia, hasta fines del siglo XIX, al embate de la civilización blanca. Como bien sostiene Palermo, estos cambios fueron el resultado de un proceso de selección organizado en torno a "modalidades productivas diseñadas por los propios interesados"85.

La excepción fue la política reduccional, que intentó forzar a los indigenas a adoptar las formas productivas hispanas, pero su escaso éxito no modifica de modo significativo lo arriba expresado. No obstante es claro, como se ha señalado oportunamente, que esta política implicó una violación evidente de las culturas indígenas. Pero si se vuelve sobre el cuadro 1. pueden comprobarse algunas diferencias: la reducción de Baradero, conformada principalmente por indios guaraní y chaná (estos últimos incluso trasladados de otra reducción en la jurisdicción de la ciudad de Santa Fe), muestra la casi totalidad de sus integrantes ya cristianizados, a la inversa de lo que ocurre en las otras dos. El carácter más sedentario del grupo y la mayor antigüedad del contacto de las etnias con los europeos pueden explicar la diferencia. En las otras predominan los grupos cazadores, lo que hacía muy difícil su sujeción, como bien lo señalan las crónicas incluidas mas arriba. Adicionalmente es probable que la atención dedicada a la reducción de Tubichaminí haya sido menor, ya que se ubica en un área muy marginal del espacio dominado por la ciudad, al menos en el período considerado.

84 Algo ya ha adelantado A. Tapia en el texto citado.

85 Palermo (1988: 44). 


\section{Bibliografia citada}

ARECES, Nidia y otros (1993) "Santa Fe la Vieja frontera abierta y de guerra. Los frentes Charrúa y chaqueño" en: Memoria Americana. Cuaderno de etnohistoria nro. 2 - Buenos Aires - Facultad de Filosofía y Letras de la UBA, pp. 7-40.

CANALS FRAU, Salvador (1940) Los indios del distrito de Buenos Aires según el repartimiento de 1582 Buenos Aires - Coni.

CANALS FRAU, Salvador (1986) Las poblaciones indigenas de la Argentina. Buenos Aires - Hypamérica.

CONLAZO, Daniel (1990) Los indios de Buenos Aires (siglos XVI-XVII). Buenos Aires Yucán.

CORDERO, Héctor (1978) El primitivo Buenos Aires. Buenos Aires - Plus Ultra.

GIBERTI, Horacio C. E. (1970) Historia económica de la ganadería argentina. Buenos Aires - Solar/Hachette.

GONZÁLEZ LEBRERO, Rodolfo E. (1994) "Impacto socio-demográfico y ambiental de la invasión europea en la zona rioplatense (1580-1640)" Ponencia presentada en las IV Jornadas de Investigación en Ciencias Sociales, organizadas por la Universidad Nacional de Jujuy.

HERNÁNDEZ, Isabel (1992) Los indios de Argentina Madrid - Mapfre.

LEVILLIER, Roberto (1915) Correspondencia de Buenos Aires con los reyes de España . 3 tomos, Madrid.

LOTHROP, Samuel K. (1932) "Indígenas del Paraná (Argentina)" versión mimeo traducida del original (publicado en: Annals of de New York Academy of Sciencies, Vol. XXXIII Nueva York, pp. 77-232) por Osvaldo C. Chiri y Marta Barciela.

LOZANO, Pedro (1873) Historia de la conquista del Paraguay, Rio de la Plata y Tucumán. Buenos Aires - Imprenta popular - Tomo 1.

MADRAZO, Guillermo (1973) "SÍNTESIS DE ARQUEOLOGÍA PAMPEANA" en: ETNIA, 17, Olavarría, pp. 13-25.

MANDRINI, Raúl (1992) "Indios y fronteras en el área pampeana (siglos XVI-XIX). Balance y perspectivas" en: Anuario IHES nro. 7, Tandil, pp. 59-74.

MANDRINI, Raúl (1993) "Las transformaciones de la economía indígena bonaerense (ca. 1600-1820)" en: Mandrini, Raúl y Reguera, Andrea (comp.) Huellas en la tierra. Indios, 
agricultores y hacendados en la pampa bonaerense Tandil - IEHS, pp. 45-74.

MARFANY, Roberto (1940) El indio en la colonización de Buenos Aires. Buenos Aires.

MARTÍNEZ SIERRA, Ramiro (1975) El mapa de las pampas. Buenos Aires.

MAZZANTI, Diana Leonis (1993) "El período tardío en la arqueología bonaerense" en: Mandrini, Raúl y Reguera, Andrea (op. cit.) pp. 31-44.

MONTOYA, Alfredo J. (1984) Cómo evolucionó la ganadería en la época del virreinato. Buenos Aires - Plus Ultra.

MORENO, Carlos (1996) Españoles y criollos, largas historias de amores y desamores. Yendo, viniendo y poblando. Buenos Aires - Icomos.

MORENO FRAGINALS, Manuel (1977) Africa en América Latina. México - Siglo XXI/UNES$\mathrm{CO}$.

PALERMO, Miguel Angel (1986) "El hierro, factor de innovación tecnológica entre los horticultores tropicales de la antigua provincia del Paraguay (siglos XVI y XVII)" en: Cuadernos de Historia Regional nro. 7, Luján - UNLu, pp. 28-40.

PALERMO, Miguel Angel (1988) "La innovación agropecuaria entre los indígenas pampeano-patagónicos: génesis y procesos" en: Anuario IHES nro. 3, Tandil, pp. 43-90.

RODNEY, Walter (1982) De como Europa subdesarrolló a Africa. México - Siglo XXI.

RODRÍGUEZ MOLAS, Ricardo (1982) Historia social del gaucho. Buenos Aires - CEAL.

RODRÍGUEZ MOLAS, Ricardo (1985) Los sometidos de la conquista. Argentina, Bolivia y Paraguay. Buenos Aires - CEAL.

SAGUIER, Eduardo (1983) The uneven incorporation of Buenos Aires into World Trade early in the seventeenth century (1602-42). The impact of commercial capitalism under the iberian mercantilism of de Hapsburgs. Washington University.

SAGUIER, Eduardo (1993) "El mercado de mano de obra indígena, liberta y mestiza y su impacto en la estabilidad del estado colonial. El caso de las encomiendas del interior del espacio colonial rioplatense" en: Cuadernos de Historia nro. 13, Departamento de ciencias históricas de la Universidad Nacional de Chile, pp. 69-140.

SCHMIDL, Ulrico (1997) Viaje al Río de la Plata. Buenos Aires - Emecé.

SIERRA, Vicente D. (1981) Historia de la Argentina. Buenos Aires - ECA.

SILVEIRA, Mario (1991) "Análisis de los restos óseos de las excavaciones de los sectores " $\mathrm{H}$ " 
y "J" del sitio Laguna del Trompa" en: Boletín del Centro de registro del patrimonio arqueológico y paleontológico nro. 3, La Plata, pp. 105-115.

TAPIA, Alicia Haydée (1997) "Visibilidad arqueológica de la conquista en la cuenca del Paraná-Plata"; ponencia al 49vo. Congreso Internacional de Americanistas Quito Ecuador. 